\title{
变电站用应急直流充电装置的研制
}

\author{
李博 扶润泽 马季 刘涛
}

国网河南省电力公司周口供电公司

DOI:10.32629/hwr.v3i2.1926

[摘 要] 变电站直流系统是变电站非常重要的组成部分, 它的主要任务就是给继电保护装置、断路器操作、各类信号回 路提供电源。直流系统的正常运行与否, 关系到继电保护及断路器能否正确动作, 会影响变电站乃至整个电网的安全运 行。

[关键词] 选择课题；制定对策；对策实施；效果检查；标准化

\section{1 选择课题}

1.1 问题的提出

变电站直流系统是变电站二次系统重要组成部分, 为 一次设备操作和二次自动化装置运行提供直流电源。直流 系统通过充电模块将站变交流电整流为直流电向蓄电池 组充电和直接供给直流负荷, 当站用电停电时, 由蓄电池 组继续提供直流电, 极大提高了各类设备直流电源的可靠 性; 同时也可以通过为 UPS 逆变系统提供交流电源, 以保 证交流电源的持续稳定供应, 保障变电站内设备正常运 行。

直流系统通常由电池屏和直流充电屏组成, 主要由整流 充电模块系统、蓄电池组系统、监控系统、绝缘监测单元、 交流输出单元、直流输出单元等构成。其核心部件为整流充 电模块, 是直流系统的心脏。但该模块在实际运行中易发生 雷电流烧毁事故, 且故障基本无法现场维修, 匹配合适备品 备件或联系厂家更换常常需要一天甚至几天时间, 直流系统 故障, 会使得变电站用一次设备失去保护, 这将直接影响到 整个变电站安全稳定运行, 给安全可靠供电留下了极大的隐 患。

小组翻阅了并统计了国网周口供电公司二次检修班 在 2017-2018 年不同时期的直流系统故障情况共 45 次。

结论：根据调查数据, 可以看出充电模块故障时基本 无法现场维修, 需返厂维修, 是影响直流系统故障的主要 因素。

\section{2 课题查新与确定}

小组成员在万方数据、中国知网, 百度网进行搜索查新, 搜索关键词: “应急直流充电装置” 均未发现相关技术方案 可借鉴。

因此, 小组提出研制一种新型的变电站用应急直流充电 装置, 已解决直流系统故障时存在的相关问题, 并最终提出 此次 $\mathrm{QC}$ 活动课题为: 变电站用应急直流充电装置。

\section{2 制定对策}

在 PDPC 过程分析基础上, 根据 “ $5 \mathrm{~W} 1 \mathrm{H}$ ” 原则及研制应急 直流充电装置的最佳方案, 制定了对策表。

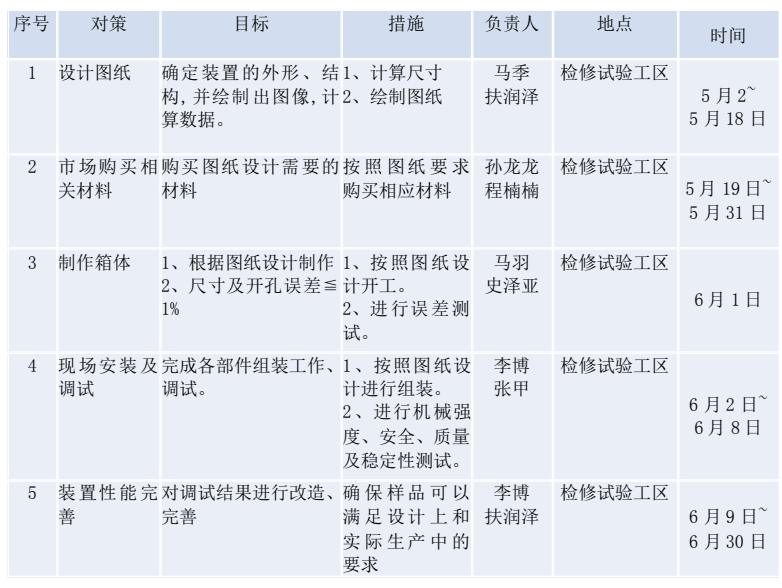

\section{1 绘制图纸}

2018 年 5 月 2-18 日, 李博做指导, 小组成员用 CAD 软件 进行变电站应急直流充电装置的图形绘制。

\section{2 材料购买}

2018 年 5 月 20 日, 按照图纸设计要求, 在市场购买静电 喷涂钢板、空气开关、导线等材料。

2.3 组装调试

小组成员李博, 张甲在检修实验工区实验室进行部件的 组装, 并进行安装调试。

\section{3 效果检查}

3.1 使用效果分析

3.1.1 结构简单、携带方便。整个装置为一体化设计, 箱体底部有四个万向轮, 内部设有输出输入端子排, 便于移 动, 接线简单。

3.1 .2 适用范围广。可针对不同型号的整流充电模块, 可有效解决各种故障。

3.1 .3 缩短停电时间、保障供电可靠性。出现故障后可 直接将应急直流充电装置接入, 不必等待厂家到场处理。

3.1. 4 降低企业成本。用于变电站二次系统改造工程中, 可明显缩短施工周期, 提高工作效率, 减少改造成本。

\section{2 效益分析}

本设计以其独到的设计眼光, 着眼于变电站安全生产环 节中的细节, 从小处抓安全、搞创新, 对于保障和提高变电站 


\section{水利工程堤坝防渗漏技术研究}

何艳芬

广西南宁市江南区六思水库管理所

DOI:10.32629/hwr.v3i2.1879

[摘 要] 堤坝, 简单理解就是指防水拦水的建筑物和构筑物, 如果堤坝出现渗漏就会导致水溢出, 严重影响到堤坝的安全性。因 此, 水库管理所展开水利工程堤坝防渗漏工作非常有必要, 本文就对水利工程堤坝防渗漏工作的重要意义进行阐述, 并提出水 利工程堤坝防渗漏技术要点, 以期能够为水利工程堤坝防渗工作提供参考依据。

[关键词] 水利工程；堤坝防渗漏技术；重要意义；渗漏成因

修建水利工程可以有效控制水流, 防止洪涝灾害, 进而 达到除害兴利的目的, 获取更多的社会经济效益。但是在水 利工程建设规模不断扩大的背景下, 堤坝渗漏问题变得越来 越严峻, 所产生的效益也逐渐降低。因此, 水库管理所需要积 极展开水利工程堤坝防渗漏工作, 本文就对水利工程堤坝防 渗漏技术进行探究, 以期提高水利工程建设质量。

\section{1 水利工程堤坝防渗漏工作的重要意义阐述}

水利工程堤坝在长时间的使用下, 由于缺少维修养护环 节, 就会出现严重的渗水漏水问题, 甚至丧失基本的水资源 调控能力, 无法将基本的功能发挥出来。而水利工程作为一 项重要的民生工程, 一旦出现渗漏问题, 就会影响到洪水的 拦截、干旱时期的水量调整、农业引水灌溉、水利发电等多 项工作, 导致农业行业发展和人们正常生活受到影响 ${ }^{[1]}$ 。针 对此种情况, 水库管理所就需要积极展开水利工程的堤坝防 渗工作, 其重要意义主要体现在以下两个方面: 一方面, 通过 水利工程堤坝防渗漏工作可以提高堤坝质量, 实现防洪、水 力发电等多项功能, 且还可以为附近的地区提供自来水及灌 溉用水, 从根本上解决水利水电工程中潜藏的问题。另一方 面, 通过水利工程堤坝防渗工作可以提高坝体变形稳定性,

\section{设备、人身及电网安全, 具有重大意义。}

使用变电站用应急直流充电装置, 提高了工作效率。极 大缩短了直流系统恢复时间, 保证了电网的稳定运行。不仅 为公司带来了良好经济效益, 同时也带来了无形的社会效 益。

\section{4 标准化}

4.1 成果巩固

小组将 “应急直流充电装置” 的操作方法和相关资料汇 总, 进行查漏补缺, 严谨认真的对待收尾工作。现已授理国家 知识产权局 “实用新型专利”。

\section{2 成果推广}

我们将 “应急直流充电装置” 的加工图纸、设计资料、 试验数据和施工步骤整理归档, 经运维检修部审批, 列入到 《周口供电公司变电运行规程》中。
对相关自然灾害进行有效预防, 从而有效提高水利工程建设 质量, 满足行业发展需求。

\section{2 水利工程堤坝防渗漏施工中存在的问题分析}

由于水利工程堤坝渗漏问题产生的原因多种多样, 常见 的有: 堤坝裂缝、渗漏管破裂、堤坝护坡坞塌、堤坝使用年 限太久等等 ${ }^{[2]}$, 无论是哪一种原因引发的堤坝渗漏问题, 都 会产生严重的经济损失, 并增加堤坝后期管理工作的难度。 目前, 水库管理所在展开水利工程堤坝防渗漏施工阶段还存 在各式各样的问题, 以下就对其中两点进行简要分析, 以供 了解:

一是, 水利工程堤坝防渗漏施工中存在施工材料质量不 合格的问题。众所周知, 水利工程规模大, 施工环节复杂, 所 需要施工的施工材料非常多, 而目前由于采购人员综合素质 和专业素质偏低, 在采购材料阶段经常为了一己私利去购买 价格低廉、防水性能差的施工材料, 这些施工材料一旦应用 到水利工程堤坝中, 就会出现老化速度快、容易脆裂等问题, 难以保证堤坝防渗功能, 制约行业的发展。

二是, 水利工程堤坝防渗漏施工中存在施工人员技术不 成熟的问题 ${ }^{[3]}$ 。水利工程堤坝防渗漏施工技术多种多样, 如,

此次 QC 活动从问题的提出到应急直流充电装置的研制, 得到了部门领导的大力支持, 在讨论及研制的过程中, QC 活 动极大的调动了班组成员的主观能动性和创造性, 提高了班 组的凝聚力。通过本次活动的开展, 小组成员的创新意识、 问题意识、改进意识、参与意识有了明显的提高, 有力促进 了课题的实施和完成, 达到了预期的目标, 取得了显著的效 益。另外, 小组成员的整体素质也得到了较大提高。

\section{[参考文献]}

[1]高凌宇.变电站直流监控系统的实现[J].中国科技财 富,2011,(10):75.

[2]吴晖,梁青云. 基于 GPRS 技术的变电站直流设备监控 系统[J].电力自动化设备,2009,29(5):117-119.

[3] 严篠丰. 变电站直流电源监控系统分析 [J]. 卷 宗,2011,(8):46.

\section{5 结束语}

